\title{
The maestro of minds
}

\section{With a mathematician's logic and the perfectionism of a concert pianist, Nikos Logothetis is making waves in cognitive neuroscience - and putting the German town of Tübingen on the scientific map. Alison Abbott pays him a visit.}

$\mathbf{N}$ ikos Logothetis could have been a professional musician: as a student, he used to play the piano in Greek bars to earn his tuition fees. And his undergraduate training in mathematics nearly took him into physics. But his bedside reading in those formative years eventually led him to biology, for which neuroscientists can count themselves lucky.

Today, Logothetis is at the top of his field. His experimental rigour commands widespread respect, and he is churning out a stream of redhot papers. More importantly, his meticulous experiments have advanced the brain-imaging technique of functional magnetic resonance imaging (fMRI) as a respectable scientifictool.

Logothetis seems both pleased and slightly embarrassed by such accolades. During our interview, he frets about seeming conceited as we discuss his achievements. Such are the troubles of a bone fide polymath. Logothetis speaks six languages, and studied musicfor seven years at the Athens Conservatory in Greece. But music was always a companion, not a profession. His first love was mathematics. Yet after completing a degree in the subject from the University of Athens in 1977, Logothetis was unsure about how to apply his training.

First, he toyed with the idea of going into physics, but worried that the certainties of 'hard science' would prove insufficiently challenging. Then, soon after graduating, he fell under the spell of a book on his bedside table: Chance and Necessity by Jacques Monod, the French molecular geneticist who shared the 1965 Nobel prize in medicine for his work on the genetic regulation of enzyme synthesis. Logothetis was particularly struck by Monod's chapter on molecular cybernetics, which introduced him to the concept of systems control in biology. ${ }^{\alpha}$ That chapter was a true revelation for me and decisive in starting $\mathrm{my}$ biology studies," Logothetis says.

\section{Universal talent}

Although Logothetis had previously dismissed biology as being " too descriptive and soft", he immediately embarked on a second undergraduate degree in the subject at the Aristotle University of Thessaloniki. There, he was introduced to neurobiology, which became his professional obsession only at the very end of the course.

After rushing through a $\mathrm{PhD}$ in neuroscience at the Ludwig-Maximilians University in Munich, Logothetis moved to the United

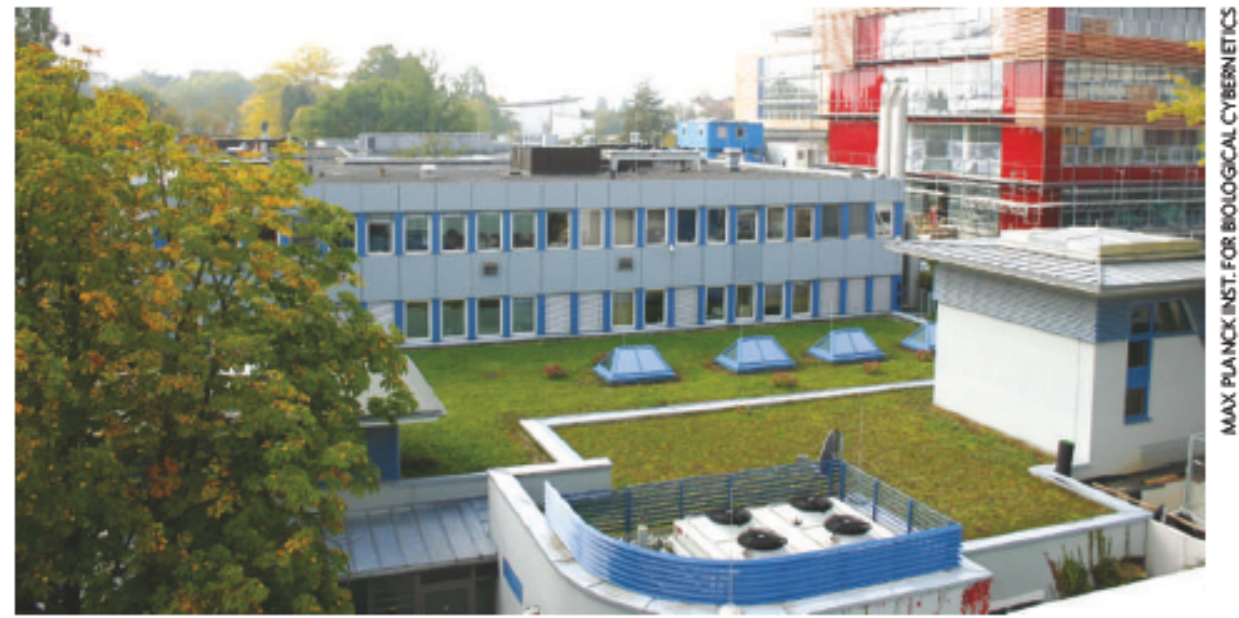

The expanding Max Planck Institute for Biological Cybemetics in Tübingen is luring topneuroscientists.

States for 12 years. He first worked at the Massachusetts Institute of Technology (MIT) in Cambridge, Massachusetts, as a postdoctoral fellow and later as a research scientist, and then joined the faculty of the Division of Neuroscience at Baylor College of Medicine in Houston, Texas.

Logothetis's main research focus has always been visual perception - understanding what goes on in our brains when we perceive and recognize objects. During his early career, Logothetis worked mostly by recording the activity of single neurons using sensitive electrodes, he still uses such techniques for a major part of his work. But during the 1990s, Logothetis became increasingly involved in fMRI. This variant of MRI was then becoming a fashionable research tool, but was also acquiring a degree of notoriety. Some scientists were making exaggerated claims for its ability to locate the precise anatomical locations of particular cognitive processes.

Logothetis has no patience with such lack of rigour. He admits to having an "obsessivecompulsive attention to detail", and soon gained a reputation for careful and elegant fMRI studies. The brain is a very accommodating structure," he warns. "It will let you generate a mass of data and interpret them to support your idea." The key, he says, is strict quality of methodology and keeping the ears resolutely plugged against the siren song of over-interpretation.

More fundamentally, Logothetis was frustrated that no one had fully tested the underlying assumption behind fMRI. In most $\mathrm{fMRI}$ studies, the main signal recorded, known as BOLD, is a measure of changes in oxygen levels in the brain, caused by variations in blood flow. But until Logothetis entered the fray, nobody had confirmed that these fluctuations actually correlate with neuronal activity.

\section{Head hunting}

In 2001, after painstaking studies in which he compared traditional electrophysiological recordings in anaesthetized monkeys with fMRI scans, Logothetis and his colleagues finally pinned down the neural correlate of the BOLD signal. This turned out to be 'local field potentials' - not the firing of individual cells, but the more slowly varying electrical activity of groups of cells as they receive and integrate information ${ }^{1}$. The paper was immediately hailed as a tour de force of experimental dexterity and data analysis ${ }^{2}$, and in 2003 was the most highly cited study in biology, apart from a handful of genome papers.

By the time his landmark paper was published, Logothet is had been back in Europe for several years. In the mid-1990s, he had been in hot demand, and was vigorously pursued by Germany's Max Planck Society, which installed him as director of the Max Planck Institute for Biological Cybernetics in Tübingen. There, he was given the best available facilities, including high-magnetic-field-strength $\mathrm{fMRI}$ machines, and state-of-the-art facilities for caring for experimental primates.

But happy as he was to be back in Europe, it wasn't long before Logothetis started to feel oppressed by the isolation of Tübingen - a smallish provincial town away from major 


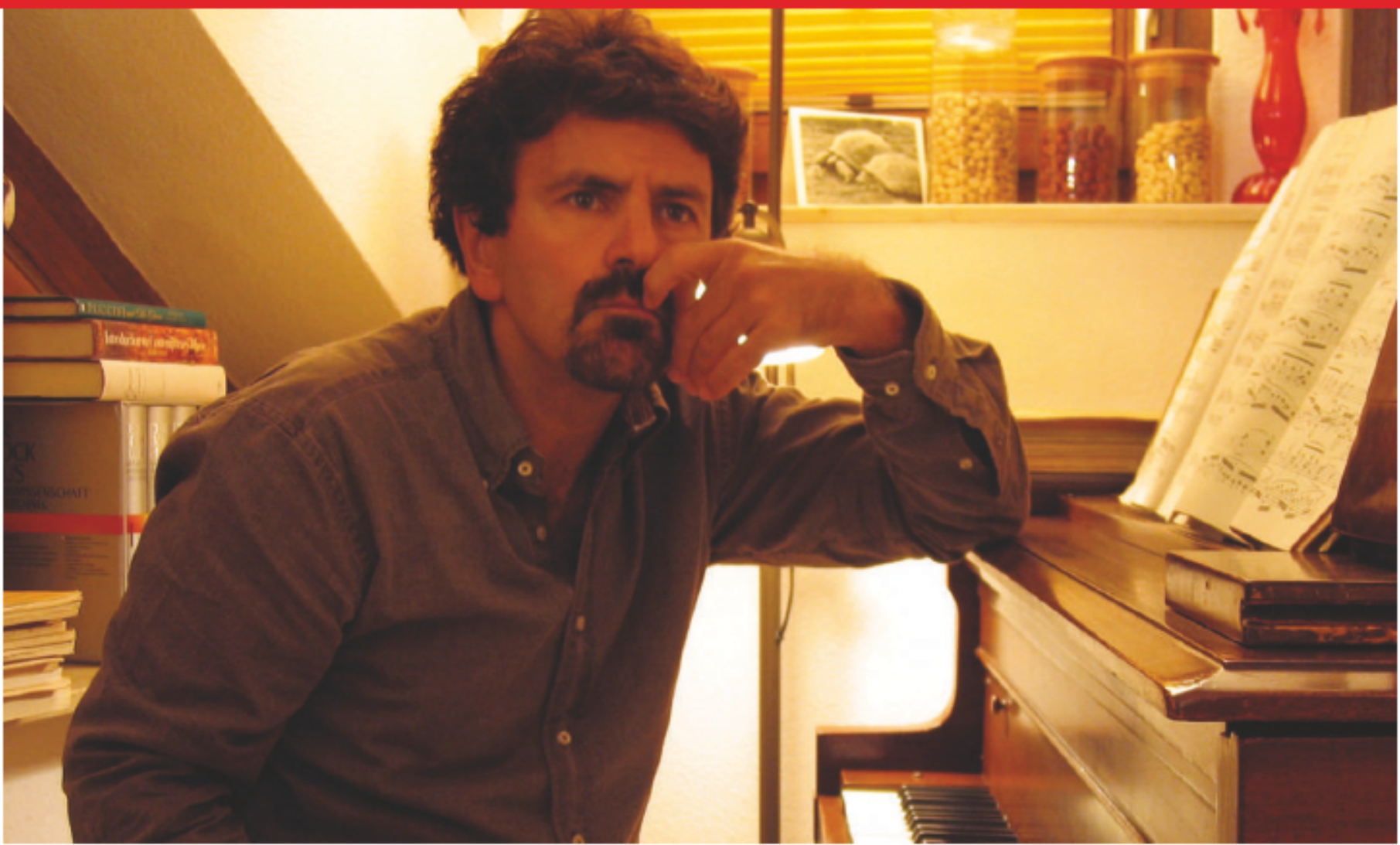

Multi-talented: now a leader in the field of cognitive neuroscience, Nikos Logothetis studied music for seven years and could have been a concer t pianist

intellectual centres. Then, in 1997, came an offer to head the prestigious new McGovern Brain Research Institute at MIT, being set up with a donation of around US\$350 million from the computer publishing magnate Pat McGovern and his wife Lore Harp McGovern.

Extraordinary steps were taken to keep Logothetis in Germany. Hubert Markl, the president of the Max Planck Society at the time, worked hard to find a way to transfer Logothetis's entire department to a larger city. Frankfurt, which boasts a high level of neuroscience research activity, was front runner.

\section{Done deal}

Negotiations opened up, but regional politics blocked the efforts. So Markl vowed instead to bring the mountain to Mohammed. A critical mass of high-level neuroscientists must be attracted to Tübingen, he declared. Markl aimed to recruit a leading technical expert in brain imaging, who could land Tübingen in pole position in the race to develop the next generation of $\mathrm{MRI}$ machines. That person was Kamil Ugurbil from the University of Minnesota, who has now been appointed director of the Tübingen Institute's new department for high-field magnetic resonance. $\mathrm{A} € 22$-million (US\$27-million) building is currently being built to accommodate Ugurbil's team and three new fMRI machines.

Meanwhile, the German Research Foundation (DFG), Germany's main research granting agency, lobbied for a new neuroscience institute planned by the charitable Hertie Foundation to be established in Tübingen. The Hertie Institute for Clinical Brain Research opened its new building in May last year. With 150 staff, the institute will work on conditions such as Alzheimer's disease.

Safe in the knowledge that a critical mass of neuroscientists are gathering around him, Logothetis is now settled. He has expanded his own department to more than 60 people and his head is a cauldron of plans. He is still not convinced that we understand enough about the neural events underlying fMRI recordings. The local field potentials that correlate with the BOLD signal, for instance, are affected by many different components of the brain's electrical activity. ${ }^{\alpha}$ We must understand the

\section{"I prefer to work more like a postdoc than a research director."}

$$
\text { - Nikos Logothetis }
$$

relation between the fMRI signal and all those components," says Logothetis.

Providing the answers will mean pushing the experimental envelope on all fronts. Logothetis plans to use 'tetrodes' - electrodes with four contact points - to follow in more detail what is going on in several neurons simultaneously. Those recordings will then be integrated with studies in neuropharmacology, optical spectroscopy and molecular imaging. Making sense of the resulting data will push even Logothetis's mathematical skills to the limit.

Logothetis is also using high-field fMRI machines as spectrometers to record the levels of individual neurotransmitters. And together with chemists at the University of
Tübingen, he is developing a sophisticated MRI contrast agent which changes its magnetic properties when it is exposed to calcium, allowing the calcium to bevisualized. This, he hopes, will provide a direct signal for the fluxes of calcium ions that accompany the transmission of neural impulses. "If the molecular signalling works, then maybe we would not need to know so much about the BOLD signal," he jokes.

Meanwhile, Logothetis's meticulous fMRI studies continue to make waves among neuroscientists. In one recent paper ${ }^{3}$, he argued that the visual cortex does not reorganize itself following damage to the retina. If Logothetis is right, he will have overturned a large body of literature which claims, using recordings from single neurons, that such reorganization does occur. Although the jury is still out, few who are familiar with Logothetis's work would bet against him being right.

Unlike many lab chiefs, Logothetis says he will continue to deploy the hands-on skills that made his name. "I prefer to work more like a postdoc than a research director," he says. "I like to do experiments myself.' Typically, he runs experiments in the mornings and crunches data until the small hours. Then it's time for the maestro to wind down: if he's lucky, he fits in half an hour on his piano before a short night's sleep.

Alison Abbott is Nature's senior European correspondent.

1. Logothetis, N. K, Pauls, L,Augath, M_ Trinath, T.\&
Oeltermann, A. Nature 412, 150-157(2001).

Oeltermann, A. Nature 412, 150-157(2001)

3. Smimakis, S. Met al. Nature 435, 300-307(2005). 